\title{
CHAPTER 38 \\ The Influence of Experience and Deliberate Practice on the Development of Superior Expert Performance
}

\author{
K. Anders Ericsson
}

There are several factors that influence the level of professional achievement. First and foremost, extensive experience of activities in a domain is necessary to reach very high levels of performance. Extensive experience in a domain does not, however, invariably lead to expert levels of achievement. When individuals are first introduced to a professional domain after completing their basic training and formal education, they often work as apprentices and are supervised by more-experienced professionals as they accomplish their work-related responsibilities. After months of experience they typically attain an acceptable level of proficiency, and with longer experience, often years, they are able to work as independent professionals. At that time most professionals reach a stable, average level of performance, and then they maintain this pedestrian level for the rest of their careers. In contrast, some continue to improve and eventually reach the highest levels of professional mastery.

Traditionally, individual differences in the performance of professionals have been explained by an account given by Galton (1869/1979, see Ericsson, 2003a, for a description). According to this view, every healthy person will improve initially through experience, but these improvements are eventually limited by innate factors that cannot be changed through training; hence attainable performance is constrained by one's basic endowments, such as abilities, mental capacities, and innate talents. This general view also explains age-related declines in professional achievement owing to the inevitable degradation of general capacities and processes with age (see also Krampe \& Charness, Chapter 40). More recently, researchers of expert performance have found that there are many types of experience and that these different types have qualitatively and quantitatively different effects on the continued acquisition and maintenance of an individual's performance (Ericsson, 1996, 2002; Ericsson, Krampe, \& Tesch-Römer, 1993). This framework proposes that some types of experience, such as merely executing proficiently during routine work, may not lead to further improvement, and that further improvements depend on deliberate efforts to change particular aspects of performance. 
In this chapter I will review evidence on the effects of experience and deliberate practice on individual differences in the acquisition of skilled and expert performance. I will first describe the traditional account of individual differences in performance based on experience and innate talent. Then I will review evidence on the effects of various types of experience on performance, especially the effects of deliberate practice. In the last half of the chapter I will discuss how deliberate practice can account for the changes in the structure of the mechanisms that mediate the superior performance of experts.

\section{The Traditional View of Skill Acquisition and Professional Development: History and Some Recent Criticisms}

Ideas about how experience and training can explain individual differences in attained level of performance have a long history. The contemporary view of lifespan development (Denney, 1982) is based on the assumption that children develop their abilities during childhood and can reach their innate potential under favorable experiential conditions. Further, the general view is that the individual's potential is limited by innate biological capacities that will ultimately constrain the highest level of achievement. Sir Francis Galton is often recognized for articulating this view in the 19th century. His pioneering book, Hereditary Genius (Galton, 1869/1979), presented evidence that height and body size were determined genetically. Most importantly, he argued that innate mechanisms also regulated size and characteristics of internal organs, such as the nervous system and the brain, and thus must similarly determine mental capacities. Galton (1869/1979) clearly acknowledged the need for training and practice to reach high levels of performance in any domain. However, he argued that improvements of performance for mature adults are rapid only in the beginning of training and that subsequent increases diminish, until "Maximal performance becomes a rigidly determinate quantity" (p. 15). According to Galton, the relevant heritable capacities determine the upper bound for the performance that an individual can attain through practice, and reflect the immutable limit that "Nature has rendered him capable of performing" (p. 16). According to Galton, the characteristics that limit maximal performance after all benefits of training have been gained must, therefore, be innately endowed. Galton's arguments for the importance of innate factors for attaining the highest levels of performance were compelling and, thus, have had a lasting impact on our culture's view of ability and expertise.

Contemporary theories of skill acquisition (Anderson, 1982; Fitts \& Posner, 1967) are consistent with Galton's general assumptions about basic unmodifiable capacities and with observations on the general course of professional development. When individuals are first introduced to a skilled activity such as driving a car, typing on a computer, or playing golf, their primary goal is to reach a level of proficiency that will allow them to perform these everyday tasks at a functional level. During the first phase of learning (Fitts \& Posner, 1967), beginners try to understand the requirements of the activity and focus on generating actions while avoiding gross mistakes. This phase is illustrated in the lower arrow in Figure 38.1 . In the second phase of learning, when people have had more experience, noticeable mistakes become increasingly rare, performance appears smoother, and learners no longer need to focus as intensely on their performance to maintain an acceptable level. After a limited period of training and experience frequently less than 50 hours for most everyday activities such as typing, playing tennis, and driving a car - an acceptable level of performance is typically attained. As individuals adapt to a domain during the third phase of learning, their performance skills become automated, and they are able to execute these skills smoothly and with minimal effort (as is illustrated in the lower arrow in Figure 38.1 . As a consequence of automatization, performers lose the ability to control 


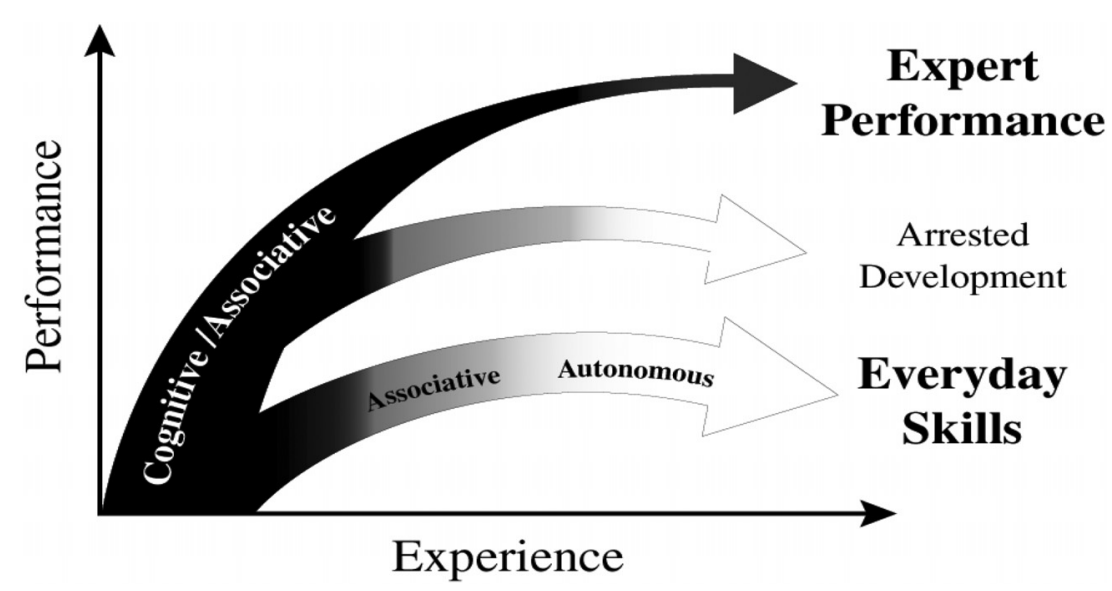

Figure 38.1. An illustration of the qualitative difference between the course of improvement of expert performance and of everyday activities. The goal for everyday activities is to reach as rapidly as possible a satisfactory level that is stable and "autonomous." After individuals pass through the "cognitive" and "associative" phases, they can generate their performance virtually automatically with a minimal amount of effort (see the gray/white plateau at the bottom of the graph). In contrast, expert performers counteract automaticity by developing increasingly complex mental representations to attain higher levels of control of their performance and will therefore remain within the "cognitive" and "associative" phases. Some experts will at some point in their career give up their commitment to seeking excellence and thus terminate regular engagement in deliberate practice to further improve performance, which results in premature automation of their performance. (Adapted from "The scientific study of expert levels of performance: General implications for optimal learning and creativity" by K. A. Ericsson in High Ability Studies, 9, p. 90. Copyright 1998 by European Council for High Ability.)

the execution of those skills, making intentional modifications and adjustments difficult (see Hill \& Schneider, Chapter 37). In the automated phase of learning, performance reaches a stable plateau, and no further improvements are observed - in agreement with Galton's (1869/1979) assumption of a performance limit.

Similar phases of acquisition and automatization have been shown to account for development in professional domains, such as telegraphy (Bryan \& Harter, 1897, 1899) and typing (Book, 1925a, 1925 b). Whereas initial proficiency in everyday and professional skills may be attained within weeks and months, development to very high levels of achievement appear to require many years or even decades of experience. In fact, Bryan and Harter claimed already in 1899 that over ten years are necessary for becoming an expert. In their seminal theory of expertise, Simon and Chase (1973) proposed that future experts gradually acquired patterns and knowledge about how to react in situations by storing memories of their past actions in similar situations. Hence, performance is assumed to improve as a consequence of continued experience. Chase and Simon's (1973) research on chess masters extended the pioneering work by de Groot (1946/1978) and demonstrated that the masters' recall for briefly presented regular game positions was vastly superior to less-skilled players. Simon and Chase (1973) argued that the masters must have acquired some 50,000 chunks or patterns to enable them to retrieve the appropriate moves for the current position in a chess game. They highlighted the parallels between reaching this highly skilled performance in chess and acquiring other cognitive skills, such as speaking a foreign language with its large 
vocabulary of many thousands of words. They found that players must have played chess for at least ten years before they are able to win international chess tournaments. In a similar vein, every healthy child requires many years of experience of listening and speaking before they are able to master their first language with its extensive vocabulary.

Some scientists started to consider the possibility that expertise was an automatic consequence of lengthy experience, and they considered individuals with over ten years of full-time engagement in a domain to be experts. These scientists typically viewed expertise as an orderly progression from novice to intermediate and to expert, where the primary factors mediating the progression through these stages were instruction, training, and experience. Thus, the primary criteria for identifying experts were social reputation, completed education, accumulated accessible knowledge, and length of experience in a domain (over ten years) (Chi, Glaser, \& Farr, 1988; Hoffman, 1992).

Several reviews over the past decade (Ericsson et al., 1993; Ericsson \& Kintsch, 1995; Ericsson \& Lehmann, 1996; Ericsson \& Smith, 1991; Vicente \& Wang, 1998) have raised issues about this characterization of expertise. Most importantly, when individuals, based on their extensive experience and reputation, are nominated by their peers as experts, their actual performance is occasionally found to be unexceptional. For example, highly experienced computer programmers' performance on programming tasks is not always superior to that of computer science students (Doane, Pellegrino, \& Klatzky, 1990), and physics professors from UC Berkeley were not always consistently superior to students on introductory physics problems (Reif \& Allen, 1992). More generally, level of training and experience frequently has only a weak link to objective measures of performance. For example, the length of training and professional experience of clinical psychologists is not related to their efficiency and success in treating patients (Dawes, 1994), and extensive experience with software design is not associated with consistently superior proficiency on presented tasks (Rosson, 1985; Sonnentag, 1998). Similarly, when wine experts are required to detect, describe, and discriminate characteristics of a wine without knowledge of its identity (i.e., seeing the label on the bottle), their performance is only slightly better than those generated by regular wine drinkers (Gawel, 1997; Valentin, Pichon, de Boishebert, \& Abdi, 2000). More generally, reviews of decision making (Camerer \& Johnson, 1991; Shanteau \& Stewart, 1992) show that experts' decisions and forecasts, such as financial advice on investing in stocks, do not show a reliable superiority over novices and thus must not improve simply with added experience. Similar absence of improvement by experienced individuals considered experts has been documented in several other areas (Ericsson \& Lehmann, 1996; Ericsson, 2004). There are even examples, such as diagnosis of heart sounds and $\mathrm{x}$ rays by general physicians (Ericsson, 2004) and auditor evaluations (Bédard \& Chi, 1993), in which performance decreases systematically in accuracy and consistency with the length of professional experience after the end of formal training.

Once it is clear that social and simple experience-based indicators of expertise do not guarantee superior performance, an alternative approach is required. Ericsson and Smith (1991) proposed that the focus should not be on socially recognized experts, but rather on individuals who exhibit reproducibly superior performance on representative, authentic tasks in their field. For example, the focus should be on physicians who can diagnose and treat patients in a superior manner, on chess players who can consistently select the best moves for chess positions, and on athletes and musicians who exhibit superior performance in competitions. The first step in a science of expert performance requires that scientists be able to capture, with standardized tests, the reproducibly superior performance of some individuals, and then be able to examine this performance with laboratory methods, as will be described in the next sections (see also, Ericsson, Chapter 13, for a more detailed treatment). 


\section{Reproducibly Superior Performance and Experience}

In many domains of expertise, individuals have been interested in assessing and comparing levels of performance under fair and controlled circumstances. For thousands of years athletes have competed under highly standardized conditions in track and field events, such as running, jumping, and throwing. These competitive conditions approach the controlled conditions generated in modern studies of performance in the laboratory. In a similar manner, musicians, dancers, and chess players have a long history of displaying their performance under controlled conditions during competitions and tournaments. Such competitions, together with similar tests, such as auditions, serve several purposes beyond identifying the best performers and presenting awards. For younger and developing performers, successful performance at competitions and auditions is necessary to gain access to the best teachers and training environments.

Ericsson and Smith (1991) discussed how one could use similar techniques to measure various types of professional expertise. We argued that a complete understanding of the structure and acquisition of excellence will be possible only in domains in which experts exhibit objectively superior performance, in a reproducible manner, for the representative activities that define the essence of accomplishment in a given domain (Ericsson, 1996, 2002). Expert performers are accustomed to performing in response to external demands, such as during emergencies in their professional practice, or at competitions and exhibitions. If they are able to reproduce their performance repeatedly on these types of occasions as well during training, they should be able to reproduce them even under laboratory conditions, a finding confirmed by recent research (Ericsson \& Lehmann, 1996).

Unfortunately, expert performance occurs naturally in complex and unique contexts, where the conditions of performance differ between performers, making comparison difficult. For example, musi- cians select their own pieces of music for their performance. Similarly, the sequence of moves in a chess game is never the same and, thus, players never encounter the exact same positions during the middle game. Fortunately, most domains of expertise require that experts be able to exhibit superior performance for presented representative situations. Ericsson and Smith (1991; Ericsson, 1996) proposed a way to find representative situations that capture the essence of expert performance in a domain and call for immediate action. They also described general methods for recreating these situations in the laboratory and then instructing experts and less skilled individuals to reproduce their performance under controlled laboratory conditions, so that investigators can identify the responsible mediating mechanisms.

Representative tasks that have been found to capture the essence of expertise in three domains are illustrated in Figure 38.2 (see treatments of these and other fields in Sections 5). In each example, the measured performance is closely related to the naturally occurring performance. To study chess expertise, players at different skill levels are asked to generate the best move for the same chess positions that have been taken from actual games between chess masters, which are not publicly available. Different typists are presented the same material and asked to type as much as possible during a fixed time period. Musicians are asked to play familiar or unfamiliar pieces of music while being recorded, and are then asked to repeat their performance exactly. When musicians are instructed to repeat their original performance, experts' consecutive renditions show much less variation than renditions by less-skilled musicians and, by implication, experts exhibit greater control over their performance.

When a review of evidence is restricted to only the reproducible superior performance of experts, obtained under directly comparable conditions, it is possible to examine several claims about the relation between expert performance and experience that generalize across domains. First, extensive 


\section{Domain}

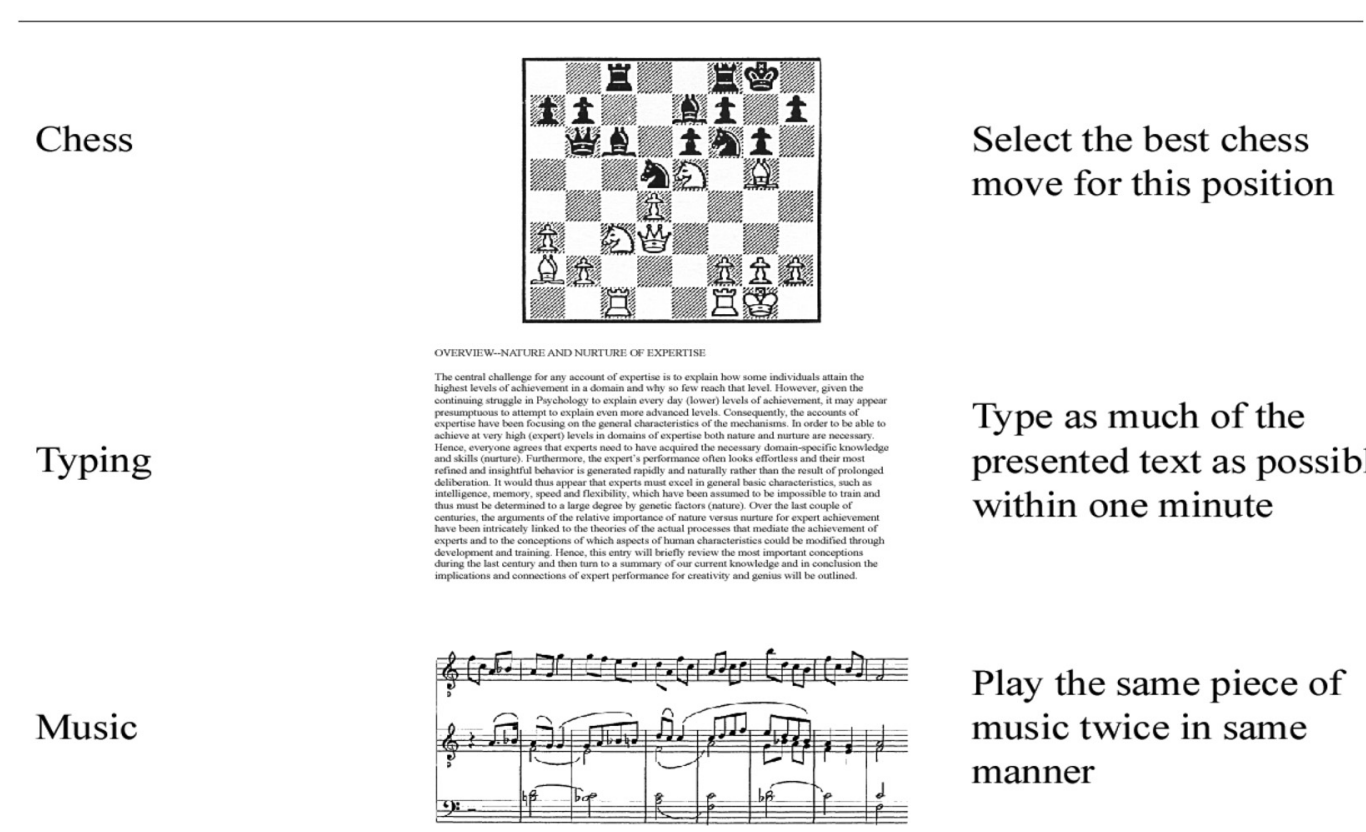

Figure 38.2. Three examples of laboratory tasks that capture the consistently superior performance of domain experts in chess, typing, and music. (From "Expertise," by K. A. Ericsson and Andreas C. Lehmann, 1999, Encyclopedia of Creativity. Copyright by Academic Press.)

experience is shown to be necessary to attain superior expert performance. Second, only some types of domain-related experience are shown to lead to improvement of performance. In addition, many thousands of hours of specific types of practice and training have been found to be necessary for reaching the highest levels of performance.

\section{The Necessity of Domain-Specific Experience for Attaining Reproducibly Superior Performance}

Recent reviews (Ericsson, 1996; Ericsson \& Lehmann, 1996) show that extended engagement in domain-related activities is necessary to attain expert performance in that domain. The availability of standardized tests allows us to measure the level of performance during development and to compare these longitudinal data to uniform adult standards. Hence, we can describe the development of expert performance as a function of age and years of experience, as fol- lows. First, longitudinal assessments of performance reveal that all individuals improve gradually, as illustrated in Figure 38.3. There is no objective evidence that a child or adult is able to exhibit a high level of performance without any relevant prior experience and practice. Similarly, there is no evidence for abrupt improvements of reproducible performance when it is tested on a monthly or yearly basis. When the performance of child prodigies in music and chess are measured against adult standards, they show gradual, steady improvement over time. Second, elite performance keeps improving beyond the age of physical maturation - the late teens in industrialized countries (Ulijaszek, Johnston, \& Preece, 1998) and is, thus, not directly limited by the functional capacity of the body and brain. Peak performance of experts is nearly always attained in adulthood - many years, and even decades, after initial exposure to the domain, as illustrated in Figure 38.3 . The age at which performers typically reach their 


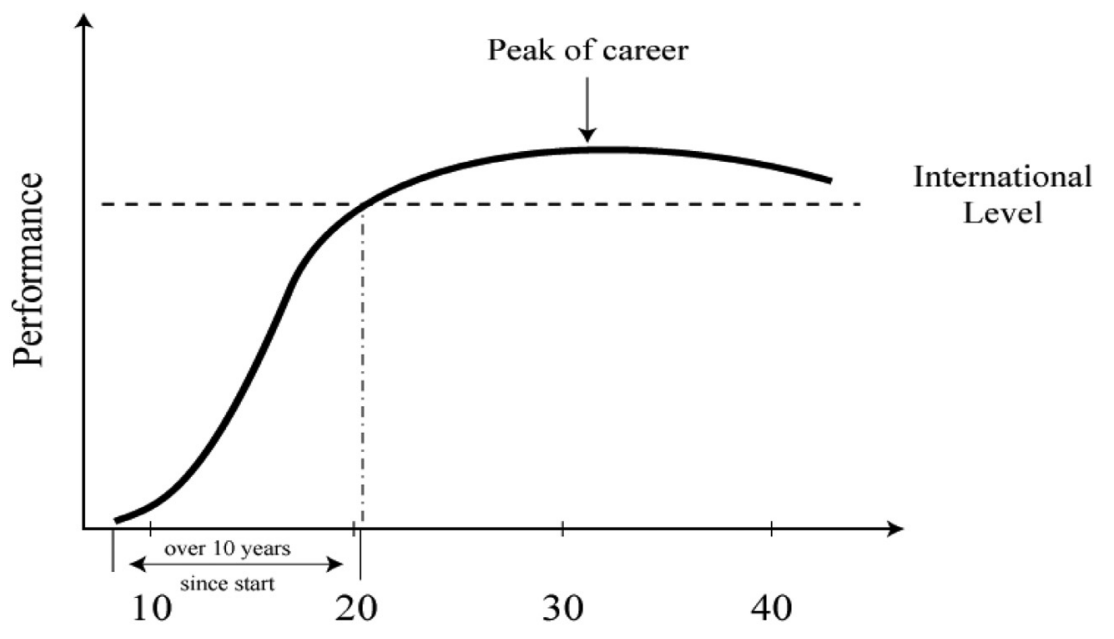

Age

Figure 38.3. An illustration of the gradual increases in expert performance as a function of age, in domains such as chess. The international level, which is attained after more than around ten years of involvement in the domain, is indicated by the horizontal dashed line. (From "Expertise," by K. A. Ericsson and Andreas C. Lehmann, 1999, Encyclopedia of Creativity. Copyright by Academic Press.)

highest level of performance in many vigorous sports is the mid- to late 20 s. For the arts and science, it is a decade later, in the 30 and 40 s (see Schulz \& Curnow, 1988, and Simonton, 1997, for reviews). The continued and often extended development of expertise past physical maturity shows that additional experience is necessary to attain one's highest level of performance.

Finally, the most compelling evidence for the role of vast experience in expertise comes from investigators who have shown that, even for the most talented individuals, ten years of experience in a domain (ten-year rule) is necessary to become an expert (Bryan \& Harter, 1899) and to win at an international level (Simon \& Chase, 1973). Subsequent reviews have shown that these findings extend to international-level success in music composition (Hayes, 1981), as well as to sports, science, and the arts (Ericsson, Krampe, \& Tesch-Römer, 1993). A closer examination of the evidence for the ten-year rule shows that the number ten is not magical. In fact, the number of years of intense training required to become an internationally acclaimed performer dif- fers across domains. For example, elite musicians (disregarding the biased standards for child prodigies) need closer to 20 to 30 years of training and often peak when they are around 30 to 40 years old. Further, outstanding scientists and authors normally published their first work at around age 25, and their best work follows around ten years later (Raskin, 1936).

Other investigators have pointed to potential exceptions to the ten-year rule. Some of the exceptions are so close to the ten-year rule that they support the necessity for around ten years to win at the international level. For example, famous chess player Bobby Fischer required nine years of intense chess study before being recognized as a grand master in chess at age 16 (Ericsson et al, 1993). Other examples suggest clearer violations. Very tall basketball players (around seven feet) have been able to reach the highest professional ranks in less than ten years of training - in around six years. Research on training of memory experts has shown that individuals can reach the highest level in the world after less than a couple of years training (Ericsson, 2003 b; 
Ericsson, Delaney, Weaver, \& Mahadevan, 2004). More generally, people are able to reach world-class levels in fewer than ten years in activities that lack a history of organized international competition. In addition, there is solid evidence that the highest levels for performance in a given domain are not stable but sometimes continue to increase over historical time as a function of progressively higher and more effective levels of training and practice.

\section{Increases in Performance over Historical Time: The Relation between Performance and Improved Methods of Practice}

In virtually every aspect of human activity there have been increases in the efficiency and level of performance. Over centuries and millennia, across domains of expertise, people have developed methods for accumulating and preserving discovered knowledge and skills and produced tools and refined their technique of application. Hence, they have assembled a body of organized knowledge that can be transferred from the current to the next generation through instruction and education (Ericsson, 1996; Feldman, 1994). It is no longer necessary for individuals to discover the relevant knowledge and methods by themselves. Today's experts can rapidly acquire the knowledge originally discovered by the pioneers. For example, in the $13^{\text {th }}$ century Roger Bacon argued that, using the thenknown methods of learning (self-study), it would be impossible to master mathematics in less than 30 to 40 years (Singer, 1958). Today, the roughly equivalent material (calculus) is taught in highly organized and accessible form in every high school. Today the development of expert levels of achievement requires instruction by teachers that helps performers gain access to the body of domain-specific knowledge, which is expressed and accumulated in terms of predefined concepts, notation systems, equipment, and measurement devices. The increases in the level of expert performance over historical time are often taken for granted in science and sports, but the improvements in instrumentation and equipment make it difficult to find comparable tasks over large time-spans in which performance can be directly compared. However, in domains with fewer changes in tools and instruments, such as music performance with the piano and violin, today's performers readily master music that was considered unplayable by the best musicians in the 19th century. They can match or often even surpass the technical virtuosity of legendary musicians and music prodigies of the past, such as Wolfgang Amadeus Mozart (Lehmann \& Ericsson, 1998).

In sports, the increases in performance over time are well known and even today world records are broken on a regular basis. In some events, such as the marathon, swimming, and diving, many dedicated amateurs and college athletes perform at a much higher level in the 2 sst century than the gold medal winners of the early Olympic Games. For example, after the IVth Olympic Games in 1908, organizers almost prohibited the double somersault in dives because they believed that these dives were dangerous, and no human would ever be able to control them. More generally, record-breaking levels of performance are nearly always originally attained by only a single eminent performer. However, after some time, other athletes are able to design training methods that allow them to attain that same level of performance. Eventually, these training methods become part of regular instruction, and all elite performers in the domain are expected to attain the new higher standard. Perhaps the most well-known example is Roger Bannister's first ever sub-four-minute mile. The earlier record for the mile had been viewed as the ultimate limit for performance, but after Bannister broke the four-minute barrier, several other runners were able to do so within a couple of years (Denison, 2003). Over time, differences in practice methods have become so great that Olympic swimmers from early in the last century would not even qualify for swim teams at today's competitive high schools (Schulz \& Curnow, 1988). In some competitive domains, such as baseball, it is 
sometimes difficult to demonstrate the increased level of today's performers because both the level of the pitcher and batter has improved concurrently (Gould, 1996). In spite of the increases in the average level of elite performance over historical time, the variability in individual differences in athletes' performance remains large a topic that will be addressed in the next section.

\section{From Experience to Designed Practice}

Many individuals seem satisfied in reaching a merely acceptable level of performance, such as amateur tennis players and golfers, and they attempt to reach such a level while minimizing the period of effortful skill acquisition. Once an acceptable level has been reached, they need only to maintain a stable performance, and often do so with minimal effort for years and even decades. For reasons such as these, the length of experience has been frequently found to be a weak correlate of job performance beyond the first two years (McDaniel, Schmidt, \& Hunter, 1988). In addition, extensive watching is not the same as extensive playing. Williams and Davids (1995), for example, found large differences in the ability to anticipate events in soccer between players and avid spectators. The select group of individuals who eventually reach very high levels do not simply accumulate more routine experience of domain-related activities but extend their active skill-building period for years or even decades, both forward and backward in time. In particular, from retrospective interviews of international-level performers in many domains, Bloom (1985a; see chapter by Sosniak, Chapter 16) showed that elite performers are typically introduced to their future realm of excellence in a playful manner at a young age. As soon as they enjoy the activity and show promise compared to peers in the neighborhood, their parents help them seek out a teacher and initiate regular practice. Bloom and his colleagues (Bloom 1985b) demonstrated that performers that reach an international level have received remarkable support by their parents and teachers (see also Mieg, Chapter 41 ). The parents of the future elite performers were even found to spend large sums of money for teachers and equipment, and to devote considerable time to escorting their child to training and weekend competitions. In some cases, the performers and their families even relocate to be closer to the chosen teacher and the training facilities. Based on their interviews, Bloom (1985 a) argued that access to the best training resources was necessary to reach the highest levels.

At the same time the best training environments are not sufficient to produce the very best performers, and there are substantial individual differences even among individuals in these environments. Can differences in the amount and type of domainrelated activities that individuals engage in explain individual differences in music performance even among the best performers? Expert violinists at the music academy in Berlin kept a weekly diary on how much time they spent during a week on different activities (Ericsson et al., 1993). All groups of expert violinists were found to spend about the same amount of time (over 50 hours) per week on music-related activities. However, the best violinists were found to spend more time per week on activities that had been specifically designed to improve performance, which we call "deliberate practice." A prime example of deliberate practice is the expert violinists' solitary practice in which they work to master specific goals determined by their music teacher at weekly lessons. The same groups of expert violinists, along with a group of professional violinists from world-class symphony orchestras, were also interviewed to estimate the amount of deliberate practice in which they had engaged during their musical development. Even among these elite groups we were able to find that the most accomplished musicians had spent more time in activities classified as deliberate practice during their development. Figure 38.4 shows that these differences were reliably observable before their admittance to the academy at around age 18 . By the age of 20 , the best 


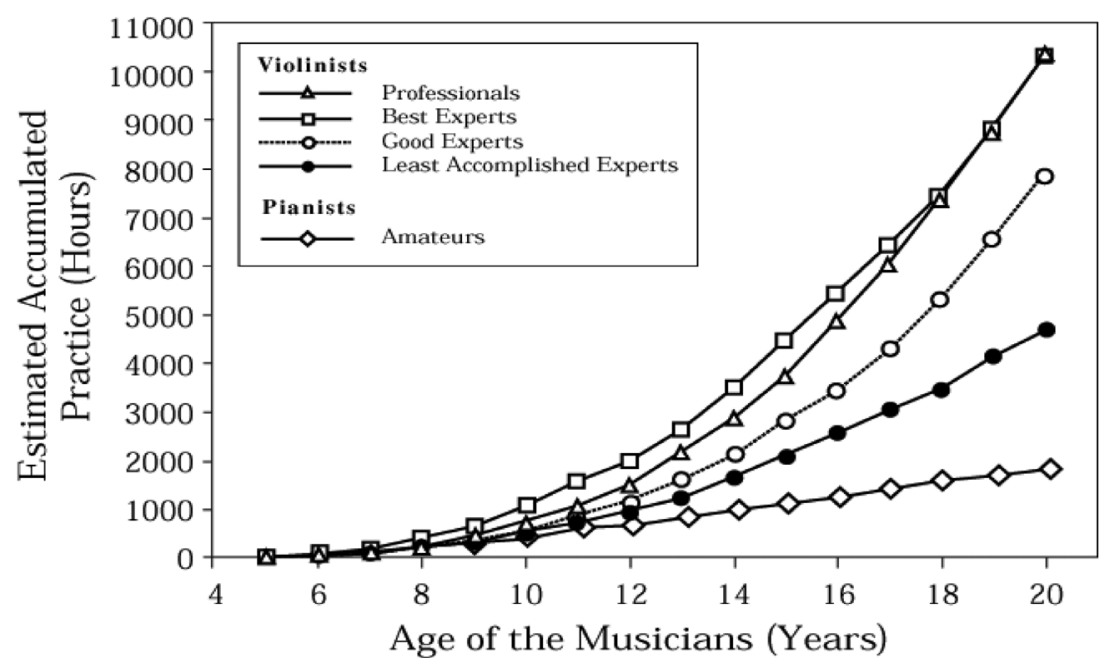

Figure 38.4 . Estimated amount of time for solitary practice as a function of age for the middle-aged professional violinists (triangles), the best expert violinists (squares), the good expert violinists (empty circles), the least accomplished expert violinists (filled circles), and amateur pianists (diamonds). (From "The role of deliberate practice in the acquisition of expert performance," by K. A. Ericsson, R. Th. Krampe, and C. Tesch-Römer, 1993, Psychological Review, 100 (3), p. 379 and p. 384 . Copyright 1993 by American Psychological Association. Adapted with permission.)

musicians had spent over 10,000 hours practicing, which averages 2,500 and 5,000 hours more than two less-accomplished groups of musicians at the same academy, respectively (Ericsson et al., 1993). In comparison to amateur pianists of the same age (Krampe \& Ericsson, 1996), the best musicians from the academy and the professionals had practiced 8,000 more hours.

The core assumption of deliberate practice (Ericsson, 1996, 2002, 2004; Ericsson et al., 1993) is that expert performance is acquired gradually and that effective improvement of performance requires the opportunity to find suitable training tasks that the performer can master sequentially typically the design of training tasks and monitoring of the attained performance is done by a teacher or a coach. Deliberate practice presents performers with tasks that are initially outside their current realm of reliable performance, yet can be mastered within hours of practice by concentrating on critical aspects and by gradually refining performance through repetitions after feed- back. Hence, the requirement for concentration sets deliberate practice apart from both mindless, routine performance and playful engagement, as the latter two types of activities would, if anything, merely strengthen the current mediating cognitive mechanisms rather than modify them to allow increases in the level of performance. Research is currently reevaluating claims that some individuals can improve their level of performance without concentration and deliberate practice. Even the well-known fact that more "talented" children improve faster in the beginning of their music development appears to be in large part due to the fact that they spend more time in deliberate practice each week (Sloboda, Davidson, Howe \& Moore, 1996). In a recent study of singers Grape, Sandgren, Hansson, Ericsson, and Theorell (2003) revealed reliable differences of skill in the level of physiological and psychological indicators of concentration and effort during a singing lesson. Whereas the amateur singers experienced the lesson as self-actualization and an enjoyable release 
of tension, the professional singers increased their concentration and focused on improving their performance during the lesson.

In other domains it has been more difficult to isolate practice activities that meet all the criteria for deliberate practice in music. In sports, several studies have found a consistent relation between attained performance and amount of practice (Helsen, Starkes, \& Hodges, 1998; Hodges \& Starkes, 1996; Starkes et al., 1996). In recent reviews of deliberate practice in sports (Côté, Ericsson, \& Law, 2005; Ericsson, 2003c; Ward, Hodges, Williams, \& Starkes, 2004), several issues have been discussed concerning the relation between different domainrelated practice activities and improvements in performance. In a study of insurance agents Sonnentag and Kleinc (2000) found that engagement in deliberate practice predicted higher performance ratings.

For example, whereas solitary training was found to distinguish elite and less-skilled performers in some sports, the amount of time spent in team-related deliberate practice activities correlates reliably with skill level in team sports (Helsen et al., 1998; Ward et al., 2004). Contrary to some evidence suggesting that playful activities, sporting diversity, and late specialization are associated with elite level sport, a quasilongitudinal study by Ward et al. (2004) demonstrated that elite-level youth soccer players did not spend more time in playful activities or in other sports or activities than their less-skilled counterparts, nor did they specialize any later. Instead, while lessskilled players spent the majority of their time in "play," elite players spent significantly longer per week and accrued more total time in deliberate practice. They perceived themselves to be more competent than the less-skilled players, and rated one of their parents as the most influential person in their career.

Rare longitudinal studies of elite performers (some of them world class, Schneider, 1993) have found that the most potent variables linked to performance and future improvements of performance involved parental support, acquired task-specific (in this case, tennis) skills, and motivational factors including concentration. Similarly in chess, Charness and his colleagues (Charness, Krampe, \& Mayr, 1996; Charness, Tuffiash, Krampe, Reingold, \& Vasyukova, 2005) found that the amount of solitary chess study was the best predictor of chess skill, and when this factor was statistically controlled, there was only a very small benefit from the number of games played in chess tournaments. Similar findings have been obtained by Duffy, Baluch, and Ericsson (2004) for dart throwing. In a particularly interesting study McKinney and Davis (2004) examined successful handling of emergency situations during flying by expert pilots. They found that if prior to the emergency event the expert pilots had practiced the same emergency situation in the simulator, they were reliably more successful in dealing with the actual event. More generally, Deakin, Côté, and Harvey (Chapter 17) review evidence on methods for recording the amount and structure of deliberate practice, using diary methods and other kinds of observations.

In this handbook several chapters discuss the role of deliberate practice in relation to self-regulated learning (Zimmerman, Chapter 39), to successful training in simulators (Ward, Williams, \& Hancock, Chapter 14), to maintained performance in older experts (Krampe \& Charness, Chapter 40), and in creative activities (Weisberg, Chapter 42 ). Other chapters review evidence on the relation between deliberate practice and the development of expertise in many domains, such as professional writing (Kellogg, Chapter 22), music performance (Lehmann \& Gruber, Chapter 26), sports (Hodges, Starkes, \& MacMahon, Chapter 27), chess (Gobet \& Charness, Chapter 30), exceptional memory (Wilding \& Valentine, Chapter 31), and mathematical calculation (Butterworth, Chapter 32). The next section will focus on the microstructure of deliberate practice and how it leads to changes in the mechanisms that mediate expert performance. 
Deliberate Practice and the Acquisition of Complex Mechanisms Mediating Expert Performance

The fundamental challenge for theoretical accounts of expert performance is to propose how expert performers can avoid reaching a performance asymptote within a limited time period, as predicted by contemporary theories of skill acquisition and expertise (Anderson, 1982; Fitts \& Posner, 1967), and keep improving their performance for years and decades.

In the introduction of this chapter the stages of everyday skill acquisition were described. At the first encounter with a task people focus on understanding it and carefully generating appropriate actions, as illustrated in the lower arm of the previously discussed Figure 38.1. With more experience, individuals' behaviors adapt to the demands of performance and become increasingly automatized, people lose conscious control over the production of their actions and are no longer able to make specific intentional adjustments to them. For example, people have difficulty describing how they tie their shoelaces or how they get up from sitting in a chair. When the behaviors are automatized, mere additional experience will not lead to increased levels of performance.

In direct contrast to the acquisition of everyday skills, expert performers continue to improve their performance with more experience as long as it is coupled with deliberate practice. The key challenge for aspiring expert performers is to avoid the arrested development associated with automaticity and to acquire cognitive skills to support their continued learning and improvement. By actively seeking out demanding tasks often provided by their teachers and coaches - that force the performers to engage in problem solving and to stretch their performance, the expert performers overcome the detrimental effects of automaticity and actively acquire and refine cognitive mechanisms to support continued learning and improvement, as shown in the upper arm of Figure 38 .1. The expert performers and their teachers identify specific goals for improv- ing particular aspects of performance and design training activities that allow the performer to gradually refine performance with feedback and opportunities for repetition (deliberate practice). The performers will gradually acquire mechanisms that increase their ability to control, self-monitor, and evaluate their performance in representative situations from the domain and thus gain independence from the feedback of their teachers (Ericsson, 1996, 2002; Glaser, 1996). Although the overall structure of these mechanisms reflects general principles, the detailed structure and practice activities that mediate their acquisition will reflect the demands of that particular activity and thus differ from one domain of expertise to another.

According to the expert-performance approach (Ericsson, 1996, 2002, 2004), skill acquisition is viewed as an extended series of gradual changes of the physiological and cognitive mechanisms that allow the observable performance to show associated improvements. The acquisition of expert performance can thus be described as a series of relatively stable states, where each state has a set of mechanisms that mediate the execution of the associated performance (see Figure 38.5). The primary differences between two adjacent states can be physiological, where the subsequent states differ in the level of strength, endurance, or speed of critical muscular systems. Alternatively, the difference between the mechanisms of the two adjacent states might be primarily cognitive. For example, the performer might be able to better represent and monitor internal and external states during performance, which in turn allows the performer to generate and select better actions, or initiate and complete actions faster, or execute motor actions more consistently and accurately.

Another fundamental challenge to a theoretical account of the acquisition of expert performance involves describing plausible explanations of how a certain type of practice activity (deliberate practice) can change any complex State[I] into the directly following complex State $[\mathrm{I}+1]$. First, the practice activities that mediate improved 


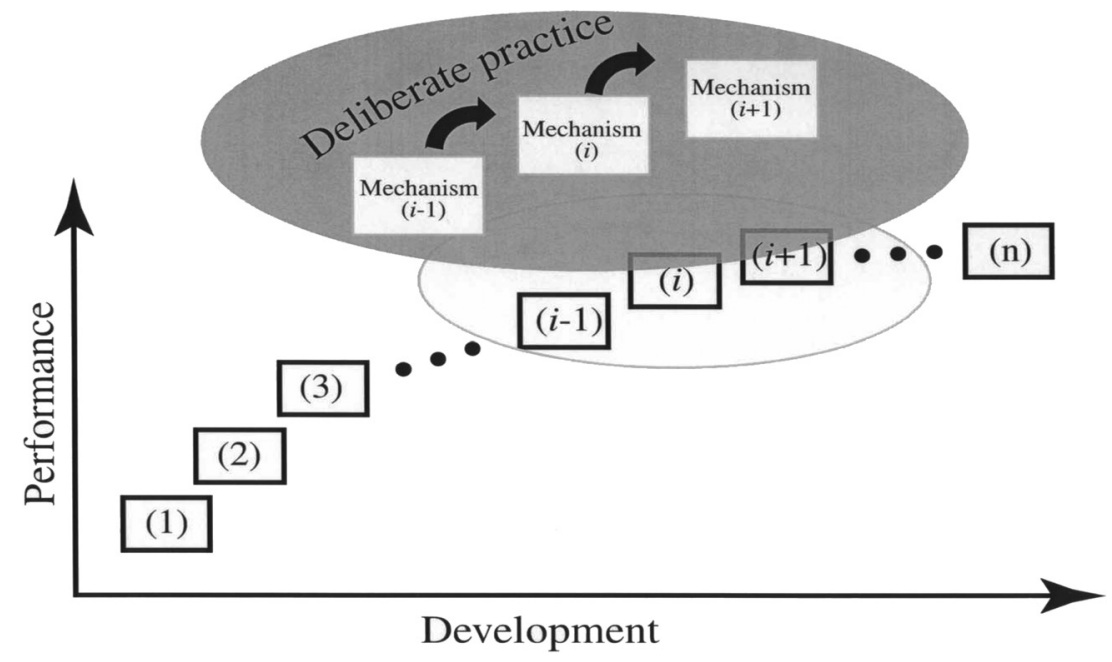

Figure 38.5 . A schematic illustration of the acquisition of expert performance as a series of states with mechanisms for monitoring and guiding future improvements of specific aspects of performance.

physiological function will be discussed, followed by a description of how practice can improve performance by changes in cognitive mechanisms that mediate performance and further learning.

\section{Improving Adaptations by Straining Physiological Systems}

Measurable increases in physical fitness do not simply result from wishful thinking. Instead people have to engage in intense aerobic exercise that pushes them well beyond the level of comfortable physical activity if they are to improve their aerobic fitness (Ericsson, 2003 a; Ericsson et al., 1993; Robergs \& Roberts, 1997). Specifically, in order to increase their aerobic fitness young adults have to exercise at least a couple of times each week, for at least 30 minutes per session, with a sustained heart rate that is $70 \%$ of their maximal level (around 140 beats per minute for a maximal heart rate of 200). When the human body is put under exceptional strain, a range of dormant genes in the DNA are expressed and extraordinary physiological processes are activated. Over time the cells of the body, including the brain (see Hill \& Schneider, Chapter 37) will reorganize in response to the induced metabolic demands of the activity by, for example, increases in the number of capillaries supplying blood to muscles and changes in metabolism of the muscle fibers themselves. These adaptations will eventually allow the individual to execute the given level of activity without greatly straining the physiological systems. To gain further beneficial increases in adaptation, the athletes need to increase or change their weekly training activities to induce new and perhaps different types of strain on the key physiological systems. For example, improvements of strength are attained when individuals lift weights to induce brief maximal efforts of the targeted muscle groups. More generally, athletic training involves pushing the associated physiological systems outside the comfort zone to stimulate physiological growth and adaptation (Ericsson, 2001, 2002, 2003a, 2003 C, 2003d). Furthermore, recent reviews (Gaser \& Schlaug, 2003; Hill \& Schneider, Chapter 37; Kolb \& Whishaw, 1998) show that the function and structure of the brain is far more adaptable than previously thought possible. Especially, early and extended training has shown to change the cortical mapping of musicians (Elbert, Pantev, Wienbruch, Rockstoh, \& Taub, 1995), the development 
of white matter in the brain (Bengtsson et al., 2005), the development of "turn out" of ballet dancers, the development of perfect pitch, and flexibility of fingers (Ericsson \& Lehmann, 1996).

In sum, elite performers search continuously for optimal training activities, with the most effective duration and intensity, that will appropriately strain the targeted physiological system to induce further adaptation without causing overuse and injury.

\section{The Acquisition of Mental Representations for Performance and Continued Learning}

One of the principal challenges to continued improvement of expert performance is that the acquired representations and mechanisms mediating expert performance must be modifiable to allow gradual changes that incrementally improve performance. They need to allow for improvements of specific aspects of the performances as well as for the coordination of necessary adjustments required by the associated changes. The experts' mental representations thus serve a dual purpose of mediating the superior expert performance while also providing the same mechanisms that can be incrementally altered to further enhance performance after practice and training. Finally, individuals must engage in deliberate-practice activities to continue to stretch their performance. The dual role of representations has been most extensively documented in chess and typing (Ericsson, 1996, 2002, 2004). Chess players rely on planning out consequences of potential moves in order to select the best move during matches in a tournament. During deliberate practice, the same chess players will rely on the same planning mechanisms to improve their ability to select the best moves. Similarly, typists rely on the same representations during performance and when they attempt to increase their speed of typing during deliberate practice. After these two examples of deliberate practice, broader issues of deliberate practice in a wide range of domains will be discussed.
CHESS

Expertise in chess was proposed by Simon and Chase (1973) to be a prototype for many domains of expertise. In his pioneering work on chess expertise, de Groot (1946/1978) uncovered the detailed processes that allow world-class chess players to analyze chess positions and to find their best move for each position. He instructed expert and worldclass players to "think aloud" while they selected the best move in a set of unfamiliar chess positions taken from games by chess masters (see Figure 38.2). Subsequent reviews related to this research showed that the quality of the selected moves was closely associated with the performers' play in tournaments and, therefore by inference, captured the essence of chess skill (Ericsson, Patel, \& Kintsch, 2000). De Groot's (1946/1978) analysis of experts' "think aloud" protocols revealed that they first formed a rapid impression of the chess position in order to retrieve potential moves from memory. These promising moves were then evaluated by mentally planning the consequences of potential options. During the course of this exercise, even the worldclass players would discover better moves, indicating that they continued to improve.

A major challenge for successful planning and chess skill is that the chess players be able to represent the chess positions in working memory in a manner that allows evaluation and flexible exploration of sequences of moves. The skills required to represent and manipulate chess positions in long-term memory appear to develop slowly as a function of increased chess skill (Ericsson \& Kintsch, 1995; Ericsson, et al., 2000). Consequently, more-skilled chess players have been shown to be able to plan more thoroughly and to represent chess positions more effectively. In addition, their memory for briefly presented chess positions is vastly superior to those of less-skilled players (Gobet \& Charness, Chapter 30). However, this superior recall performance is limited to representative chess positions and disappears almost completely when chess positions are randomly rearranged. 
The central challenge to an account of the continued improvement of a chess experts' ability is to understand how they plan and select the best action in a given game situation. Chess players typically practice this task by studying chess openings and analyzing published games between the very best chess players in the world. They typically analyze the games by playing through the games, one move at a time, to determine if their selected move matches to the corresponding move originally selected by the masters. If the master's move in the studied chess game differed from their own selection, this would imply that their planning and evaluation must have overlooked some aspect of the position. It is important to note that this learning process allows the player to diagnose the source of suboptimal moves and thus make a local change that improves the selection of related moves without causing interference with other aspects of the existing skill.

By more careful and extended analysis, the chess expert is generally able to discover the reasons for the chess master's superior move. Serious chess players spend as much as four hours every day engaged in this type of solitary study (Charness et al., 1996, 2005; Ericsson et al., 1993). By spending additional time analyzing the consequences of moves for a chess position, players can increase the quality of their selections of moves. With more study, individuals refine their representations and can access or generate the same information faster. As a result, chess masters can typically recognize a superior move virtually immediately, whereas a competent club player requires much longer to find the same move by successive planning and evaluation rather than recognition. The same type of improvement based on deliberate practice and increased depth of planning can explain gradually increased performance in a wide range of domains, such as billiards, golf, music, and surgery (Ericsson, 2004).

TYPING

If chess is viewed as one of the most intellectually challenging tasks, then typing is typically viewed as a diametrically different, mundane, habitual activity. Many adults are able to type, yet there are often large individual differences in the speed attained. The standardized measure of typing speed involves having skilled typists and unskilled participants type passages from a collection of unfamiliar texts as fast as they can without making errors. High-speed films of finger movements show that the faster typists start moving their fingers toward their desired locations on the keyboard well before the keys are struck. The superior typists' speed advantage is linked to their perceptual processing of the text beyond the word that they are currently typing (Salthouse, 1984). By looking ahead in the text to identify letters to be typed, they can prepare future keystrokes in advance. This evidence for anticipation has been confirmed by experimental studies where expert typists have been restricted from looking ahead. Under such conditions their typing speed is dramatically reduced and approaches the speed of less-skilled typists.

In sum, the superior speed of reactions by expert performers, such as typists and athletes, appears to depend primarily on cognitive representations mediating skilled anticipation (see also, Endsley, Chapter 36 ), rather than faster basic speed of their nervous system (Abernethy, 1991). For instance, expert tennis players are able to anticipate where a tennis player's shots will land even before the player's racquet has contacted the ball (Williams, Ward, Knowles, \& Smeeton, 2002). Eye movements of expert tennis players show that they are able to pick up predictive information from subtle, yet informative, motion cues, such as hip and shoulder rotation, compared to their novice counterparts. They can also use lateroccurring and more-deterministic cues, such as racket swing, to confirm or reject their earlier anticipations.

Research on instruction in typing (Dvorak, Merrick, Dealey, \& Ford, 1936) has so far provided the best initial insights into how speed of performance can be increased through deliberate practice that alters and improves the representations mediating 
anticipation and coordination of finger movements. The key empirical observation is that people can increase their typing speed by exerting full concentration toward improvement. Regular typists can typically maintain this level of concentration for only 15 to 30 minutes per day. When typists concentrate and strain themselves to type at a faster rate (typically around 10 to $20 \%$ faster than their normal speed), they strive to anticipate better, possibly by extending their gaze further ahead.

The increased tempo also brings out keystroke combinations for which the typists are comparatively slow, thus restricting a fluent higher speed. These challenging combinations can then be trained in special exercises and incorporated into the typing of regular text. This is in order to assure that any modifications can be integrated with the representations mediating typical typing tasks. By increasing anticipation and successively eliminating weaknesses, typists can increase their average speed in practice at a rate that is still 10 to $20 \%$ faster than their new average speed attained after such practice. The general approach of finding methods to push performance beyond its normal level - even if that performance can be maintained only for a short time - offers the potential for identifying and correcting weaker components that will improve performance as well as for enhancing anticipation.

\section{A Broader View of Expert Performance and Deliberate Practice}

The theoretical framework of deliberate practice asserts that improvement in performance of aspiring experts does not happen automatically or casually as a function of further experience. Improvements are caused by changes in cognitive mechanisms mediating how the brain and nervous system control performance and in the degree of adaptation of physiological systems of the body. The principal challenge to attaining expert level performance is to induce stable specific changes that allow the performance to be incrementally improved.
Once we conceive of expert performance as mediated by complex integrated systems of representations for the planning, analysis, execution, and monitoring of performance (see Figure 38.5), it becomes clear that its acquisition requires a systematic and deliberate approach. Deliberate practice is therefore designed to improve specific aspects of performance in a manner that assures that attained changes can be successfully measured and integrated into representative performance. Research on deliberate practice in music and sports shows that continued attempts for mastery require that the performer always try, by stretching performance beyond its current capabilities, to correct some specific weakness while preserving other successful aspects of function. This type of deliberate practice requires full attention and concentration, but even with that extreme effort, some kind of failure is likely to arise, and gradual improvements with corrections and repetitions are necessary. With increased skill in monitoring, skilled performers in music focus on mastering new challenges by goal-directed deliberate practice involving problem solving and specialized training techniques (Chaffin \& Imre, 1997; Ericsson, 2002; Gruson, 1988; Nielsen, 1999).

In their research on sports, Deakin and Cobley (2003) found that ice skaters spend a considerable portion of their limited practice time on jump-combinations they have already mastered, rather than working on the yet-to-be-mastered combinations, where there is the largest room for improvement. More generally, they found that with increasing levels of attained skill the skaters spent more time on jumps and other challenging activities that had the potential to improve performance.

Practice aimed at improving integrated performance cannot be performed mindlessly nor independent of the representative context for the target performance. In addition, more-accomplished individuals in the domain, such as professional coaches and teachers, will always play an essential role in guiding the sequencing of practice activities for future experts in a safe and effective 
manner. Research on self-regulated learning (Zimmerman, Chapter 39) has documented effective study methods that are related to superior academic performance, especially in high schools. More recent work has shown that engagement in study methods consistent with deliberate practice has been found to predict achievement in both undergraduate college students (Plant, Ericsson, Hill, \& Asberg, 2005) as well as in students in medical school (Moulaert, Verwijnen, Rikers, \& Scherpbier, 2004).

The deliberate-practice framework can also explain the necessity for further deliberate practice in order for individuals simply to maintain their current level of skill. It is well known that athletes and musicians who reduce or stop their regular practice will exhibit a reduced level of performance - a maintained level of challenge and strain appear necessary to preserve the attained physiological and cognitive adaptations. The same type of account has been developed to explain age-related reductions in music performance and how they can be counteracted by maintained levels of deliberate practice (Krampe \& Ericsson, 1996; see Krampe and Charness, Chapter 40).

\section{Concluding Remarks: General Characteristics of Deliberate Practice}

The perspective of deliberate practice attributes the rarity of excellence to the scarcity of optimal training environments and to the years required to develop the complex mediating mechanisms that support expertise. Even children considered to have innate gifts need to attain their superior performance gradually, by engaging in extended amounts of designed deliberate practice over many years. Until most individuals recognize that sustained training and effort is a prerequisite for reaching expert levels of performance, they will continue to misattribute lesser achievement to the lack of natural gifts, and will thus fail to reach their own potential.

The effects of mere experience differ greatly from those of deliberate practice, where individuals concentrate on actively trying to go beyond their current abilities. Consistent with the mental demands of problem solving and other types of complex learning, deliberate practice requires concentration that can be maintained only for limited periods of time. Although the detailed nature of deliberate practice will differ across domains and as a function of attained skill, there appear to be limits on the daily duration of deliberate practice, and this limit seems to generalize across domains of expertise. Expert performers from many domains engage in practice without rest for only around an hour, and they prefer to practice early in the morning when their minds are fresh (Ericsson et al., 1993). Elite musicians (Ericsson, 2002) and athletes (Ericsson, $2001,2003 \mathrm{C}$ ) report that the factor that limits their deliberate practice is primarily an inability to sustain the level of concentration that is necessary. Even more interestingly, elite performers in many diverse domains have been found to practice, on the average, roughly the same amount every day, including weekends, and the amount of practice never consistently exceeds five hours per day (Ericsson, 1996; Ericsson et al., 1993). The limit of four to five hours of daily deliberate practice or similarly demanding activities holds true for a wide range of elite performers in different domains, such as writing by famous authors (Cowley, 1959; Plimpton, 1977), as does their increased tendency to take recuperative naps. Furthermore, unless the daily levels of practice are restricted, such that subsequent rest and nighttime sleep allow the individuals to restore their equilibrium, individuals often encounter overtraining injuries and, eventually, incapacitating "burnout." In some domains of sports, such as gymnastics, sprinting, and weight lifting, the maximal effort necessary for representative performance is so great that the amount of daily deliberate practice is even further limited by factors constraining the duration of production of maximal power and strength.

The scientific study of deliberate practice will enhance our knowledge about how experts optimize the improvements of their 
performance (and motivation) through a high level of daily practice they can sustain for days, months, and years. The emerging insights should be relevant to any motivated individual aspiring to excel in any challenging domain (Ericsson, 2004). Although we are already gaining understanding about how performers improve with deliberate practice and reach expert levels, it is unlikely that we will ever be able to fully understand and predict future innovations. We may be able to reproduce the path of development that elite performers have taken to reach their highest levels of performance in the past. We may also be able to help performers in one domain of expertise, such as surgery, learn about the best training methods that have been developed in domains with a longer tradition, such as violin performance. We may even be able to work in collaboration with world-class performers who are working on improving their performance to new and undiscovered heights. At the highest levels of expert performance, the drive for improvement will always involve search and experimentation at the threshold of understanding, even for the masters dedicated to redefining the meaning of excellence in their fields.

\section{References}

Abernethy, B. (1991). Visual search strategies and decision-making in sport. International Journal of Sport Psychology, 22 , 189-210.

Anderson, J. R. (1982). Acquisition of cognitive skill. Psychological Review, 89, 369-406.

Bédard, J., \& Chi, M. T. H. (1993). Expertise in auditing. Auditing, 12, (Suppl.), 1-25.

Bengtsson, S. L., Nagy, Z., Skare, S., Forsman, L., Forsberg, H., \& Ullén, F. (2005). Extensive piano practicing has regionally specific effects on white matter development. Nature Neuroscience, 8, 1148-1150.

Bloom, B. S. (1985 a). Generalizations about talent development. In B. S. Bloom (Ed.), Developing talent in young people (pp. 507-549). New York: Ballantine Books.

Bloom, B. S. (Ed.) (1985b). Developing talent in young people. New York: Ballantine Books.
Book, W. F. (1925a). Learning to typewrite. New York: The Gregg Publishing Co.

Book, W. F. (1925b) The psychology of skill. New York: The Gregg Publishing Co.

Bryan, W. L., \& Harter, N. (1897). Studies in the physiology and psychology of the telegraphic language. Psychological Review, 4, 27-53.

Bryan, W. L., \& Harter, N. (1899). Studies on the telegraphic language: The acquisition of a hierarchy of habits. Psychological Review, 6, 345375 .

Camerer, C. F., \& Johnson, E. J. (1991). The process-performance paradox in expert judgment: How can the experts know so much and predict so badly? In K. A. Ericsson and J. Smith (Eds.), Towards a general theory of expertise: Prospects and limits (pp. 195-217). Cambridge: Cambridge University Press.

Chaffin, R., \& Imreh, G. (1997). "Pulling teeth and torture": Musical memory and problem solving. Thinking and Reasoning, 3, 315336.

Charness, N., Krampe, R. Th., \& Mayr, U. (1996). The role of practice and coaching in entrepreneurial skill domains: An international comparison of life-span chess skill acquisition. In K. A. Ericsson (Ed.), The road to excellence: The acquisition of expert performance in the arts and sciences, sports, and games (pp. 51-80). Mahwah, NJ: Erlbaum.

Charness, N., Tuffiash, M. I., Krampe, R., Reingold, E., \& Vasyukova E. (2005). The role of deliberate practice in chess expertise. Applied Cognitive Psychology, 19, 151-165.

Chi, M. T. H., Glaser, R., \& Farr, M. J. (Eds.) (1988). The nature of expertise. Hillsdale, NJ: Erlbaum.

Côté, J., Ericsson, K. A., \& Law, M. (2005). Tracing the development of athletes using retrospective interview methods: A proposed interview and validation procedure for reported information. Journal of Applied Sport Psychology, 17, 1-19.

Cowley, M. (Ed.) (1959). Writers at work: The Paris review interviews. New York: Viking.

Dawes, R. M. (1994). House of cards: Psychology and psychotherapy built on myth. New York: Free Press.

Deakin, J. M., \& Cobley, S. (2003). A search for deliberate practice: An examination of the practice environments in figure skating and volleyball. In J. Starkes \& K. A. Ericsson (Eds.), Expert performance in sport: Recent advances in 
research on sport expertise (pp. 115-135). Champaign, IL: Human Kinetics.

de Groot, A. (1978). Thought and choice in chess (Original work published in 1946). The Hague: Mouton.

Denison, J. (2003). Bannister and beyond: The mystique of the four minute mile. Breakaway books.

Denney, N. W. (1982). Aging and cognitive changes. In B. B. Wolman (Ed.), Handbook of developmental psychology (pp. 807-827). Englewood Cliffs, NJ: Prentice Hall.

Doane, S. M., Pellegrino, J. W., \& Klatzky, R. L. (1990). Expertise in a computer operating system: Conceptualization and performance. Human-Computer Interaction, 5, 267-304.

Duffy, L. J., Baluch, B., \& Ericsson, K. A. (2004). Dart performance as a function of facets of practice amongst professional and amateur men and women players. International Journal of Sport Psychology, 35, 232-245.

Dvorak, A., Merrick, N. L., Dealey, W. L., \& Ford, G. C. (1936). Typewriting behavior. New York: American Book Company.

Elbert, T., Pantev, C., Wienbruch, C., Rockstroch, B., \& Taub, E. (1995). Increased cortical representation of the fingers of the left hand in string players. Science, 270, 305-307.

Ericsson, K. A. (1996). The acquisition of expert performance: An introduction to some of the issues. In K. A. Ericsson (Ed.), The road to excellence: The acquisition of expert performance in the arts and sciences, sports, and games (pp. 1-50). Mahwah, NJ: Erlbaum.

Ericsson, K. A. (2001). The path to expert performance: Insights from the masters on how to improve performance by deliberate practice. In P. Thomas (Ed.), Optimizing performance in golf (pp. 1-57). Brisbane, Australia: Australian Academic Press.

Ericsson, K. A. (2002). Attaining excellence through deliberate practice: Insights from the study of expert performance. In M. Ferrari (Ed.), The pursuit of excellence in education (pp. 21-55). Hillsdale, NJ: Erlbaum.

Ericsson, K. A. (2003a). The search for general abilities and basic capacities: Theoretical implications from the modifiability and complexity of mechanisms mediating expert performance. In R. J. Sternberg \& E. L. Grigorenko (Eds.), Perspectives on the psychology of abilities, competencies, and expertise (pp. 93-125). Cambridge: Cambridge University Press.
Ericsson, K. A. (2003b). Exceptional memorizers: Made, not born. Trends in Cognitive Sciences, 7, 233-235.

Ericsson, K. A. (2003c). The development of elite performance and deliberate practice: An update from the perspective of the expertperformance approach. In J. Starkes \& K. A. Ericsson (Eds.), Expert performance in sport: Recent advances in research on sport expertise (pp. 49-81). Champaign, IL: Human Kinetics.

Ericsson, K. A. (2003d). How the expert-performance approach differs from traditional approaches to expertise in sports: In search of a shared theoretical framework for studying expert performance. In J. Starkes \& K. A. Ericsson (Eds.), Expert performance in sport: Recent advances in research on sport expertise (pp. 371401). Champaign, IL: Human Kinetics.

Ericsson, K. A. (2004). Deliberate practice and the acquisition and maintenance of expert performance in medicine and related domains. Academic Medicine, 10, $\mathrm{S}_{1}-\mathrm{S}_{12}$.

Ericsson, K. A., Delaney, P. F., Weaver, G., \& Mahadevan, R. (2004). Uncovering the structure of a memorist's superior "basic" memory capacity. Cognitive Psychology, 49, 191-237.

Ericsson, K. A., \& Kintsch, W. (1995). Longterm working memory. Psychological Review, $102,211-245$.

Ericsson, K. A., Krampe, R. Th., \& Tesch-Römer, C. (1993). The role of deliberate practice in the acquisition of expert performance. Psychological Review, 100, 363-406.

Ericsson, K. A., \& Lehmann, A. C. (1996). Expert and exceptional performance: Evidence on maximal adaptations on task constraints. Annual Review of Psychology, 47, 273-305.

Ericsson, K. A., Patel, V. L., \& Kintsch, W. (2000). How experts' adaptations to representative task demands account for the expertise effect in memory recall: Comment on Vicente and Wang (1998). Psychological Review, 107, 578592 .

Ericsson, K. A., \& Smith, J. (1991). Prospects and limits in the empirical study of expertise: An introduction. In K. A. Ericsson \& J. Smith (Eds.), Toward a general theory of expertise: Prospects and limits (pp. 1-38). Cambridge: Cambridge University Press.

Feldman, D. H. (1994). Beyond universals in cognitive development (2nd. Ed.). Norwood, NJ: Ablex. 
Fitts, P., \& Posner, M. I. (1967). Human performance. Belmont, CA: Brooks/Cole.

Galton, F., Sir (1869/1979). Hereditary genius: An inquiry into its laws and consequences (Originally published in 1869). London: Julian Friedman Publishers.

Gaser, C., \& Schlaug, G. (2003). Brain structures differ between musicians and nonmusicians. Journal of Neuroscience, 23, 92409245 .

Gawel, R. (1997). The use of language by trained and untrained experienced wine tasters. Journal of Sensory Studies, $12,267-284$.

Glaser, R. (1996). Changing the agency for learning: Acquiring expert performance. In K. A. Ericsson (Ed.), The road to excellence: The acquisition of expert performance in the arts and sciences, sports, and games (pp. 1-50). Mahwah, NJ: Erlbaum.

Gould, S. J. (1996). Full house: The spread of excellence from Plato to Darwin. New York: Harmony books.

Grape, C., Sandgren, M., Hansson, L.-O., Ericson, M., \& Theorell, T. (2003). Does singing promote well-being?: An empirical study of professional and amateur singers during a singing lesson. Integrative Physiological \& Behavioral Science, 38, 65-71.

Gruson, L. M. (1988). Rehearsal skill and musical competence: Does practice make perfect? In J. A. Sloboda (Ed.), Generative processes in music (pp. 91-112). Oxford, UK: Clarenden Press.

Hayes, J. R. (1981). The complete problem solver. Philadelphia, PA: Franklin Institute Press.

Helsen, W. F., Starkes, J. L., \& Hodges, N. J. (1998). Team sports and the theory of deliberate practice. Journal of Sport and Exercise Psychology, 20, 12-34.

Hodges, N. J., \& Starkes, J. L. (1996). Wrestling with the nature of expertise: A sport specific test of Ericsson, Krampe and TeschRömer's (1993) theory of "Deliberate Practice." International Journal of Sport Psychology, $27,400-424$.

Hoffman, R. R. (Ed.) (1992). The psychology of expertise: Cognitive research and empirical AI. New York: Springer-Verlag.

Krampe, R. Th., \& Ericsson, K. A. (1996). Maintaining excellence: Deliberate practice and elite performance in young and older pianists. Journal of Experimental Psychology: General, $125,331-359$.
Kolb, B., \& Whishaw, I. Q. (1998). Brain plasticity and behavior. Annual Review of Psychology, 49, 43-64.

Lehmann, A. C., \& Ericsson K. A. (1998). The historical development of domains of expertise: Performance standards and innovations in music. In A. Steptoe (Ed.), Genius and the mind (pp. 67-94). Oxford, UK: Oxford University Press.

McDaniel, M. A., Schmidt, F. L., \& Hunter, J. E. (1988). Job experience correlates of job performance. Journal of Applied Psychology, 73, $327-$ 330.

McKinney, E. H., \& Davis, K. J. (2004). Effects of deliberate practice on crisis decision performance. Human Factors, 45, 436-444.

Moulaert, V., Verwijnen, M. G. M., Rikers, R., \& Scherpbier, A. J. J. A. (2004). The effects of deliberate practice in undergraduate medical education. Medical Education, 38, 1044-1052.

Nielsen, S. (1999). Regulation of learning strategies during practice: A case study of a single church organ student preparing a particular work for a concert performance. Psychology of Music, 27, 218-229.

Plant, E. A., Ericsson, K. A., Hill, L., \& Asberg, K. (2005). Why study time does not predict grade point average across college students: Implications of deliberate practice for academic performance. Contemporary Educational Psychology, 30, 96-116.

Plimpton, G. (Ed.) (1977). Writers at work: The Paris review. Interviews, Second Series. New York: Penguin.

Raskin, E. (1936). Comparison of scientific and literary ability: A biographical study of eminent scientists and letters of the nineteenth century. Journal of Abnormal and Social Psychology, 31, 20-35.

Reif, F., \& Allen, S. (1992). Cognition for interpreting scientific concepts: A study of acceleration. Cognition and Instruction, 9, 1-44.

Robergs, R. A., \& Roberts, S. O. (1997). Exercise physiology: Exercise, performance, and clinical applications. St. Louis, MO: Mosby-Year Book.

Rosson, M. B. (1985). The role of experience in editing. Proceedings of INTERACT ' 84 IFIP Conference on Human-Computer Interaction (pp. 45-50). New York: Elsevier.

Salthouse, T. A. (1984). Effects of age and skill in typing. Journal of Experimental Psychology: General, 113, 345-371. 
Schneider, W. (1993). Acquiring expertise: Determinants of exceptional performance. In K. A. Heller, J. Mönks, \& H. Passow (Eds.), International handbook of research and development of giftedness and talent (pp. 311-324). Oxford, UK: Pergamon Press.

Shanteau, J., \& Stewart, T. R. (1992). Why study expert decision making? Some historical perspectives and comments. Organizational Behaviour and Human Decision Processes, 53. 95-106.

Schulz, R., \& Curnow, C. (1988). Peak performance and age among superathletes: Track and field, swimming, baseball, tennis, and golf. Journal of Gerontology: Psychological Sciences, 43, $113-120$.

Simon, H. A., \& Chase, W. G. (1973). Skill in chess. American Scientist, 61, 394-403.

Simonton, D. K. (1997). Creative productivity: A predictive and explanatory model of career trajectories and landmarks. Psychological Review, 104, 66-89.

Singer, C. (1958). From magic to science. New York: Dover.

Sloboda, J. A., Davidson, J. W., Howe, M. J. A., \& Moore, D. G. (1996). The role of practice in the development of performing musicians. British Journal of Psychology, 87, 287-309.

Sonnentag, S. (1998). Expertise in professional software design: A process study. Journal of Applied Psychology, 83, 703-715.

Sonnentag, S., \& Kleine, B. M. (2000). Deliberate practice at work: A study with insurance agents. Journal of Occupational and Organizational Psychology, 73, 87-102.

Starkes, J. L., Deakin, J., Allard, F., Hodges, N. J., \& Hayes, A. (1996). Deliberate practice in sports: What is it anyway? In K. A. Ericsson (Ed.), The road to excellence: The acquisition of expert performance in the arts and sciences, sports, and games (pp. 81-106). Mahwah, NJ: Erlbaum.

Ulijaszek, S. J., Johston, F. E., \& Preece, M. A. (Eds.) (1998). The Cambridge encyclopedia of human growth and development. Cambridge, UK: Cambridge University Press.

Valentin, D., Pichon, M., de Boishebert, V., \& Abdi, H. (2000). What's in a wine name? When and why do wine experts perform better than novices? Abstracts of the Psychonomic Society, 5 , 36 .

Vicente, K. J., \& Wang, J. H. (1998). An ecological theory of expertise effects in memory recall. Psychological Review, 105, 33-57.

Ward. P., Hodges, N. J., Williams, A. M., \& Starkes, J. L. (2004). Deliberate practice and expert performance: Defining the path to excellence. In A. M. Williams \& N. J. Hodges (Eds.), Skill acquisition in sport: Research, theory and practice (pp. 231-258). London, UK: Routhledge.

Williams, M., \& Davids, K. (1995). Declarative knowledge in sport: A by-product of experience or a characteristic of expertise? Journal of Sport \& Exercise Psychology, 17, 259-275.

Williams, A. M., Ward, P., Knowles, J. M., \& Smeeton, N. J. (2002). Anticipation skill in a real-world task: Measurement, training, and transfer in tennis. Journal of Experimental Psychology: Applied, 8, 259-270.

\section{Author Notes}

This research was supported by the FSCW/Conradi Endowment Fund of Florida State University Foundation. The author wants to thank Andreas Lehmann, Len Hill, Robert Hoffman, and Paul Ward for the helpful comments on earlier drafts of the chapter. 
